\title{
Temperature and frequency dependences of real part of impedance in the FeCoZr-doped PZT nanogranular composites
}

\author{
Andrei V. LARkin ${ }^{1}$, Alexander K. Fedotov ${ }^{1}$, Julia A. Fedotova ${ }^{2}$, \\ TOMASZ N. KOLTUNOWICZ ${ }^{3 *}$, PAWEL ZHUKOWSKI ${ }^{3}$ \\ ${ }^{1}$ Belarusian State University, 4 Nezavisimosti Str., 220030 Minsk, Belarus \\ 2 National Center of Particles and High Energy Physics of BSU, 153 M. Bogdanovich Str., 220040 Minsk, Belarus \\ ${ }^{3}$ Lublin University of Technology, 38a Nadbystrzycka Str., 20-618 Lublin, Poland
}

The study of carrier transport in granular nanocomposite films consisting of ferromagnetic $\mathrm{Fe}_{45} \mathrm{Co}_{45} \mathrm{Zr}_{10}$ alloy nanoparticles embedded in a low-conductive $\mathrm{Pb}_{81} \mathrm{Sr}_{4}\left(\mathrm{Na}_{5} \mathrm{Bi}_{5}\right)_{15}\left(\mathrm{Zr}_{57.5} \mathrm{Ti}_{42.5}\right) \mathrm{O}_{3}$ matrix has been performed. Real part of the impedance of the nanocomposites was studied as a function of composition, temperature and frequency, for the samples with $25 \leq x \leq 80$ at. $\%$, deposited by ion-beam sputtering in $\mathrm{Ar}+\mathrm{O}_{2}$ gas mixture at the oxygen pressures of $P_{\mathrm{O}_{2}}=2.4 \cdot 10^{-3}$ and $3.7 \cdot 10^{-3} \mathrm{~Pa}$. It has been proved that approaching the threshold concentration, $x_{C}$ in the FeCoZr alloy resulted in the transition from high-ohmic to low-ohmic state with the $x$ increase, without the change of hopping mechanism of carrier transport.

Keywords: impedance, ion-beam sputtering, nanocomposites

(C) Wroclaw University of Technology.

\section{Introduction}

Nowadays, the synthesis and investigation of the granular nanocomposites containing a mixture of conductive and nonconductive phases are of a great interest for the material engineers. Particular attention is paid to the composites in which granules of soft ferromagnetic high-conductive metallic alloys with sizes of about few nanometers are randomly distributed in low-conductive matrixes. The great interest in such materials is caused by wide opportunities of their application (e.g. in high ohmic resistors, protection from high-frequency irradiation and for other purposes) [1]. The nanocomposites possess also such properties as giant magnetoresistivity, anomalous Hall effect, high magnetorefractive effect, etc., that made them prospective also for saving and recording the information in magnetic heads, for magneto-sensitive and other electronic devices [2].

It should be mentioned that the metal-dielectric and metal-piezoelectric nanocomposites are the in-

*E-mail: t.koltunowicz@pollub.pl teresting model systems to study such important and fundamental effects as percolation, hopping conductance, weak localization, etc.

In accordance with the percolation theory [3], the extreme values of physical parameters (including electrical properties) in such nanocomposites are observed near the threshold concentration $x_{C}$ of metallic elements, when a current-conductive net of such nanoparticles starts to form (for binary nanocomposites $x_{C}$ is called the "percolation threshold") resulting in the insulator-metal transition (IMT). The $x_{C}$ value is strongly dependent on the amount of high-conductive and low-conductive phases, their volume ratio and also on the concentration of chemically active impurities incorporated into the matrix and/or metallic filler during synthesis. This makes the elucidation of the correlations between the deposition conditions, volume ratio $x$, phase composition of nanoparticles, type of insulating matrix and electric properties of nanocomposite films as a whole very important. In our earlier studies [4-9] we showed that the deposition conditions are one of the key factors influencing 
the phase and magnetic state of the nanogranular films of $\left(\mathrm{Fe}_{45} \mathrm{Co}_{45} \mathrm{Zr}_{10}\right)_{x}\left(\mathrm{Al}_{2} \mathrm{O}_{3}\right)_{(100-x)}$. In particular, addition of oxygen into the vacuum chamber resulted in the formation of metallic nanoparticles with "metallic core/CoFe-based oxide shell" structure and radical modification of electric and magnetic properties of the nanocomposites studied as a whole. This formation of "core/shell" structure shifted the $x_{C}$ value up to 55 at.\% as compared to $44-47$ at.\% in the films deposited in pure Ar gas atmosphere, although the IMT was preserved.

In connection with this, the main goal of this paper was to investigate the changes in the carrier transport mechanisms in granular nanocomposites, consisting of the $\mathrm{Fe}_{45} \mathrm{Co}_{45} \mathrm{Zr}_{10}$ alloy nanoparticles embedded into low-conductive ferroelectric $\left(\mathrm{Pb}_{81} \mathrm{Sr}_{4} \mathrm{Na}_{7.5} \mathrm{Bi}_{7.5}\right)\left(\mathrm{Zr}_{57.5} \mathrm{Ti}_{42.5}\right) \mathrm{O}_{3}$ matrix, caused by the influence of partial pressure of oxygen in the deposition atmosphere in relation to $\left(\mathrm{Fe}_{45} \mathrm{Co}_{45} \mathrm{Zr}_{10}\right)_{x}\left(\mathrm{Al}_{2} \mathrm{O}_{3}\right)_{(100-x)}$ nanocomposite films, with the use of the impedance spectroscopy method [10].

\section{Experimental}

Granular nanocomposites $\left(\mathrm{Fe}_{45} \mathrm{Co}_{45} \mathrm{Zr}_{10}\right)_{x}$ $\left[\left(\mathrm{Pb}_{81} \mathrm{Sr}_{4} \mathrm{Na}_{7.5} \mathrm{Bi}_{7.5}\right)\left(\mathrm{Zr}_{57.5} \mathrm{Ti}_{42.5}\right) \mathrm{O}_{3}\right]_{(100-x)}$ were prepared in a set-up described in [11], shown in Fig. 1. We used ion-beam sputtering of compound target 5 in vacuum chamber 1 filled with pure argon + oxygen mixture under the oxygen partial pressures of $P_{\mathrm{O}_{2}}=2.4 \cdot 10^{-3} \mathrm{~Pa}$ (set 1 of samples) and $3.7 \cdot 10^{-3} \mathrm{~Pa}$ (set 2 ) during the deposition. The compound target 3 consisted of cast $\mathrm{Fe}_{45} \mathrm{Co}_{45} \mathrm{Zr}_{10}$ alloy plate covered with a system of narrow stripes of doped PZT. Irregular distribution of the stripes on the alloy plate resulted in the formation of the film with continuously changing metallic phase concentrations in the range of $30 \leq x \leq 80$ at.\% in a single technological cycle The samples under consideration were the films of 1 - $2 \mu \mathrm{m}$ thicknesses deposited on ceramic substrates and then cut normally to its length to form the rectangular samples of $2 \mathrm{~mm}$ width and $10 \mathrm{~mm}$ length with different $x$ values.

The chemical composition of the examined samples was previously verified with energy-dispersive microanalysis (EDX) and Rutherford backscattering

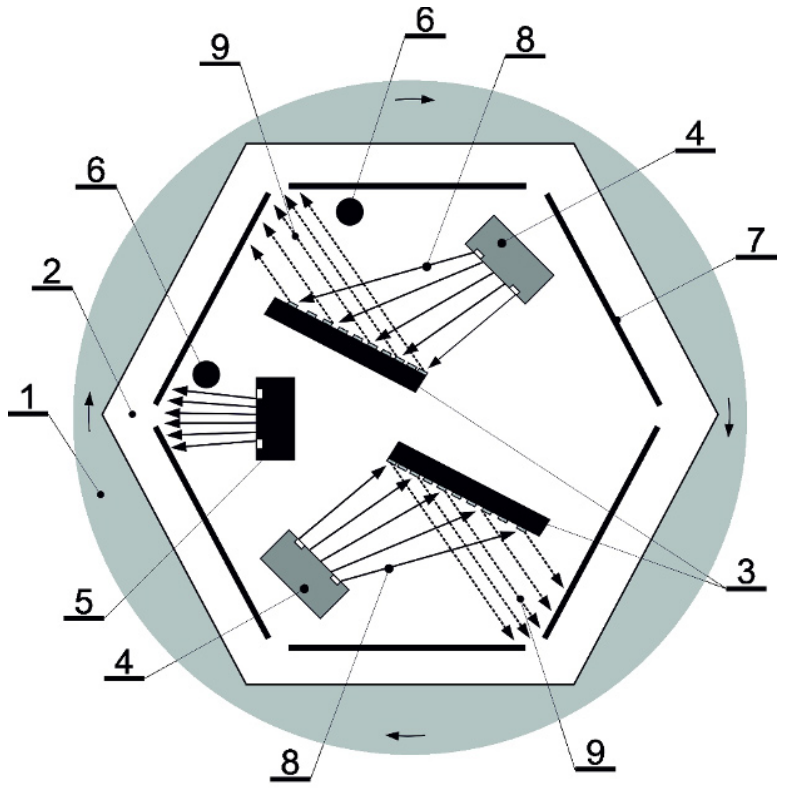

Fig. 1. Multifunctional vacuum device for ion-beam sputtering deposition: 1 - vacuum chamber; 2 rotating substrate carrier; 3 - compound targets; 4 - sources of sputtering $\mathrm{Ar}$ or $\mathrm{Ar}+\mathrm{O}_{2}$ ion-beam; 5 - source of ion etching; 6 - compensators; 7 - substrates; 8 - argon or argon + oxygen ionbeams; 9 - beams of ejected atoms.

method (RBS) in detail using Mössbauer, Raman and EXAFS spectroscopy as reported in [12-15].

The dependences of the impedance on the total FeCoZr concentration $x$, temperature and frequency were measured in the samples covered with ohmic contacts prepared by ultrasonic soldering of indium. The impedance of the samples was measured by means of a 2-probe method in the temperature range of $100-340 \mathrm{~K}$. The measurement setup included a precise ac bridge HP-4284A and a computer with frequency and temperature control system. It allowed us to conduct the measurements of current amplitude and phase in the frequency range of $10^{2}-$ $10^{6} \mathrm{~Hz}$ which were then used for the calculation of the real and imaginary parts of impedance in the examined samples.

The films thicknesses were measured with accuracy within 3-4\% on the samples chips by means of the SEM LEO 1455VP. On the whole, the relative error of impedance measurements did not exceed $5 \%$. 


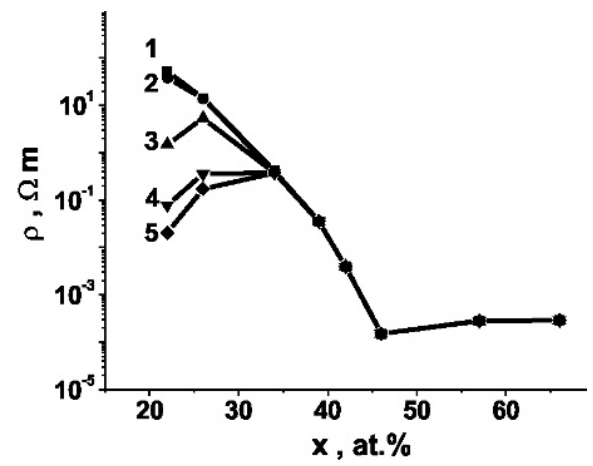

(a)

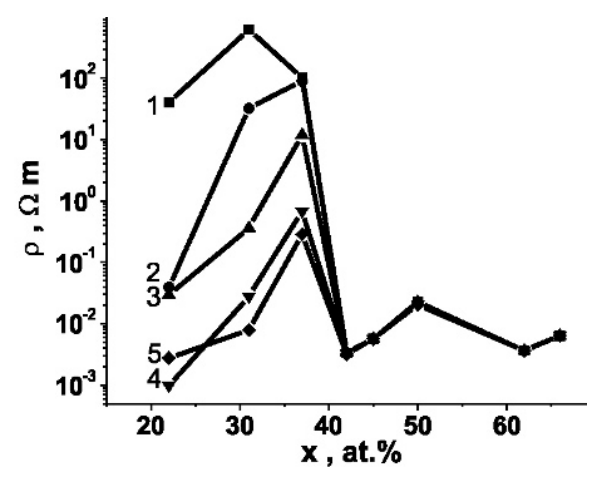

(b)

Fig. 2. Dependences of the real part of the nanocomposites impedance for the set 1 (a) and set 2 (b) of the samples for the frequencies $f=1.5 \mathrm{kHz}(1)$, $10 \mathrm{kHz}(2), 100 \mathrm{kHz}(3), 500 \mathrm{kHz}(4), 1000 \mathrm{kHz}$ (5) at the temperature of $T=300 \mathrm{~K}$.

\section{Results and discussion}

As was shown in our previous papers [4-10], the composition/frequency/temperature dependence $\rho(x, f, T)$ of the real part of impedance in the film nanocomposites $\left(\mathrm{Fe}_{45} \mathrm{Co}_{45} \mathrm{Zr}_{10}\right)_{x}\left(\mathrm{Al}_{2} \mathrm{O}_{3}\right)_{(100-x)}$, deposited in the mixture of $\mathrm{Ar}+\mathrm{O}_{2}$, showed IMT as the metallic fraction content $x$ increased. This was manifested in the change of $\mathrm{d} \rho(T) / \mathrm{d} T$ sign from negative to positive when crossing $x$ close to the value $x_{C} \approx$ 55 at.\%. As follows from the experiments presented in this paper, the concentration $\rho(x)$ and temperature/frequency $\rho(T, f)$ dependence in the examined $\left(\mathrm{Fe}_{45} \mathrm{Co}_{45} \mathrm{Zr}_{10}\right)_{x}(\mathrm{PZT})_{(100-x)}$ films, presented in Figs. 2-5, show principally different behavior in comparison to $\left(\mathrm{Fe}_{45} \mathrm{Co}_{45} \mathrm{Zr}_{10}\right)_{x}\left(\mathrm{Al}_{2} \mathrm{O}_{3}\right)_{(100-x)}$ nanocomposites.

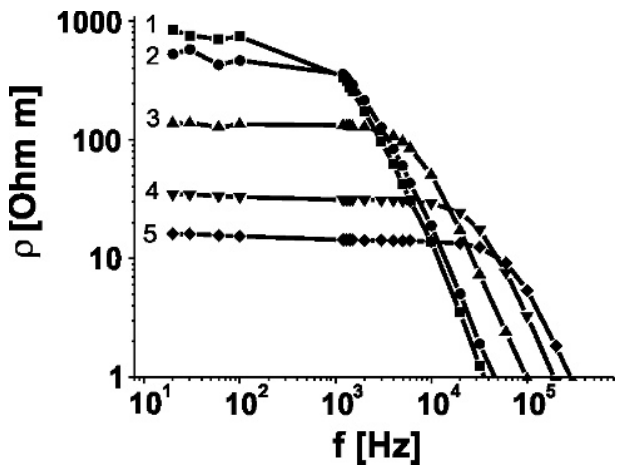

(a)

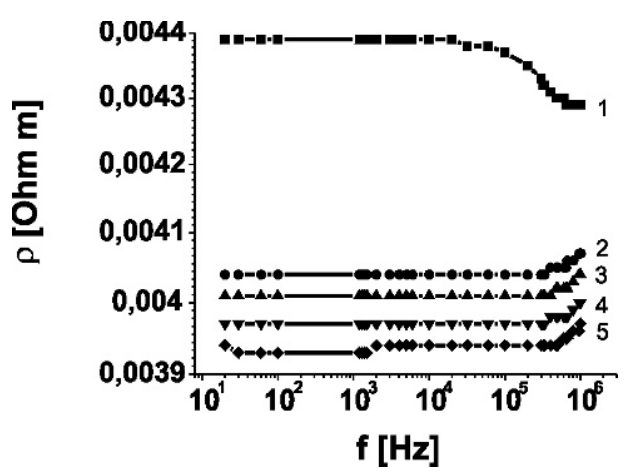

(b)

Fig. 3. Frequency dependences of the real part of impedance for the set 1 samples below (a) and above (b) the threshold concentration $x_{C 1}$ at the temperatures $T=140 \mathrm{~K}(1), 170 \mathrm{~K}(2), 230 \mathrm{~K}$ (3), $273 \mathrm{~K}(4), 300 \mathrm{~K}(5)$.

The observed dependences of the real part of impedance $\rho$ on $x$, measured at room temperature, are presented in Fig. 2. They show three main features. Firstly, the $\rho(x)$ curves lie higher on $\rho$-scale (at least, for low frequencies) by 1-2 orders of magnitude for the set 2 as compared to the set 1 samples. This evidences more advanced oxidation of nanoparticles in the set 2 samples, which was also confirmed by Mössbauer, EXAFS and Raman spectroscopies in [12-15] for the same samples.

Secondly, $\rho(x)$ dependences display a dramatic change in the progress in approaching a certain threshold concentration $x_{C}$, which depends on $P_{\mathrm{O}_{2}}$ values and is equal $x_{C 1} \approx 46$ at. $\%$ and $x_{C 2} \approx 41$ at. $\%$ for the set 1 and set 2 films, respectively. As can be seen, $\rho(x)$ behavior changes from fast monotonous decrease (by 5-6 orders of magnitude) with $x$ increase at $x<x_{C}$ to weakly variable $\rho(x)$ above the 


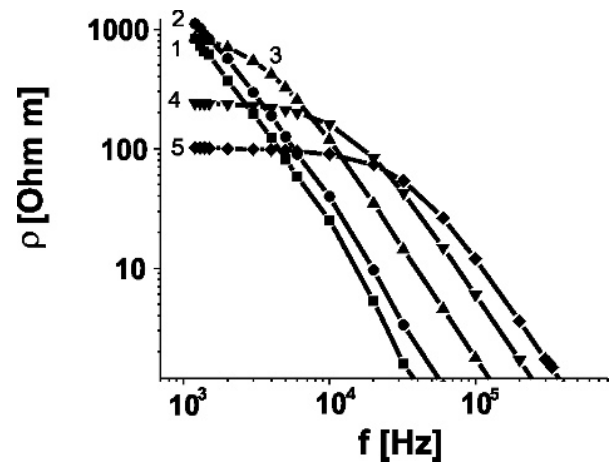

(a)

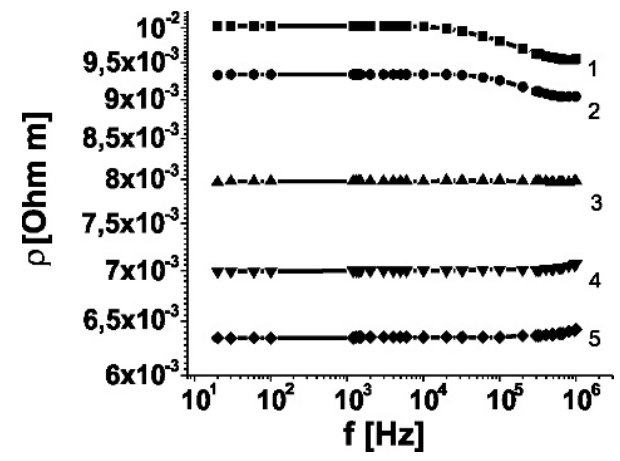

(b)

Fig. 4. Frequency dependences of the real part of the nanocomposites impedance for the $\left(\mathrm{Fe}_{45} \mathrm{Co}_{45} \mathrm{Zr}_{10}\right)_{x}(\mathrm{PZT})_{(100-x)}$ for the set 2 samples below (a) and above (b) the threshold concentration $x_{C 2}$ at the temperatures $T=140 \mathrm{~K}(1)$, $170 \mathrm{~K}(2), 230 \mathrm{~K}(3), 273 \mathrm{~K}(4), 300 \mathrm{~K}(5)$.

$x_{C}$ value with the sharp bend at $x \approx x_{C}$. Taking into account the advanced oxidation of nanoparticles revealed in [12-15] and also the behavior of $\rho(f, T)$ curves shown below in Figs. 3-6 as well as temperature dependences of dc resistance observed in [13], we can attribute the $x_{C}$ value to the concentration related to the direct electrical contact of oxidized nanoparticles. Note that the observed values of $x_{C}$ are very close to the percolation threshold position ( $\sim 50$ at.\%), predicted for 3-dimensional percolating systems by the percolation theory [3].

Thirdly, for both sets of the samples the $\rho(x)$ curves are characterized by the maximum $\rho_{\text {max }}$ at low $x$ values. As can be seen from the comparison of Figs. $2 \mathrm{a}$ and $2 \mathrm{~b}$, the position of $\rho_{\max }$ depends both on the values of oxygen partial pressure $P_{\mathrm{O}_{2}}$ and on the measurement frequency. In particular, the

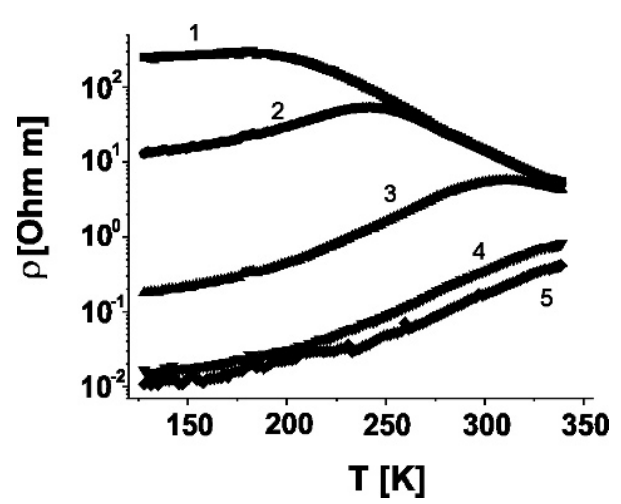

(a)

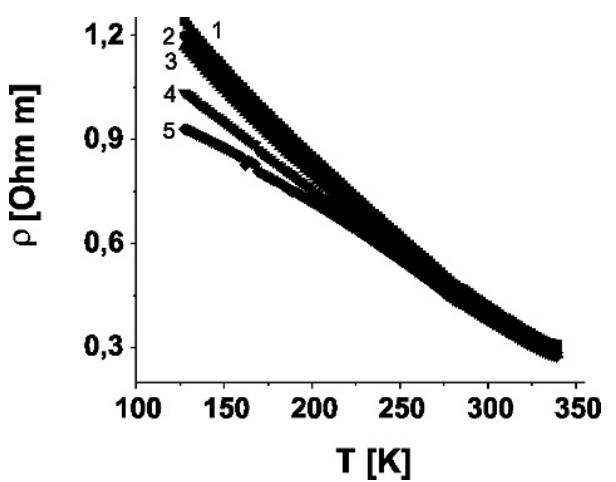

(b)

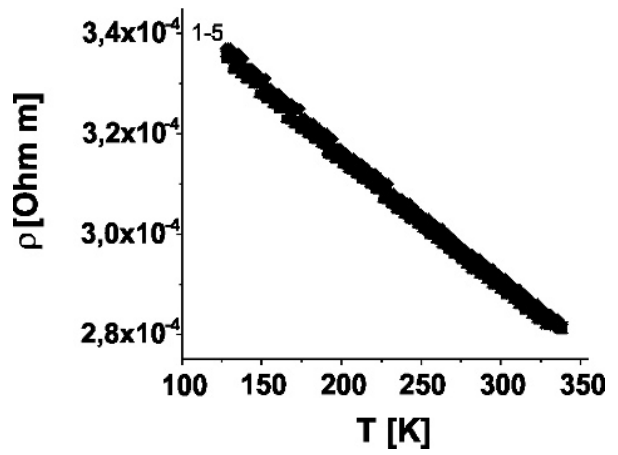

(c)

Fig. 5. Temperature dependences of the real part of the nanocomposites impedance for the set 1 samples with $x=26$ at.\% (a), 39 at.\% (b) and 66 at.\% (c) at frequencies $f=1,5 \mathrm{kHz}(1), 10 \mathrm{kHz}(2)$, $100 \mathrm{kHz}$ (3), $500 \mathrm{kHz}$ (4), $1000 \mathrm{kHz}$ (5).

$\rho_{\max }$ value is shifted to higher metal-to-dielectric ratios $x$ as the frequency increases. Note also that in the set 1 samples, deposited at lower $P_{\mathrm{O}_{2}}$ values, this maximum in $\rho(x)$ becomes apparent only at frequencies higher than $10 \mathrm{kHz}$ (see, Fig. 2a). 


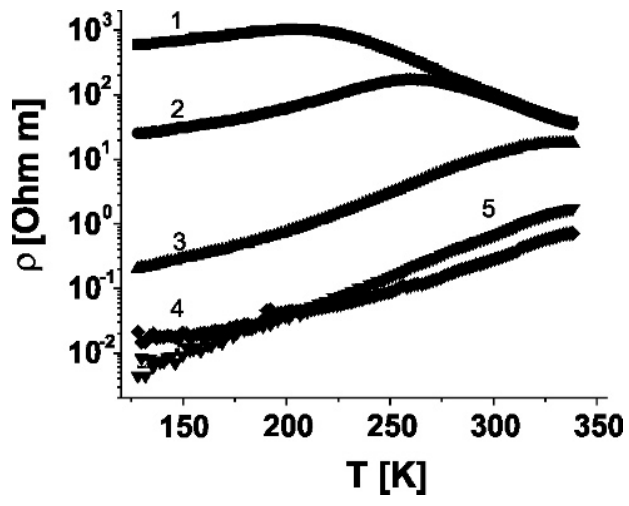

(a)

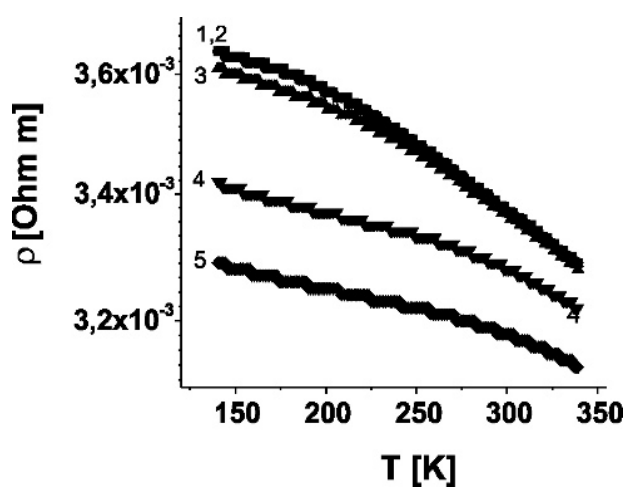

(b)

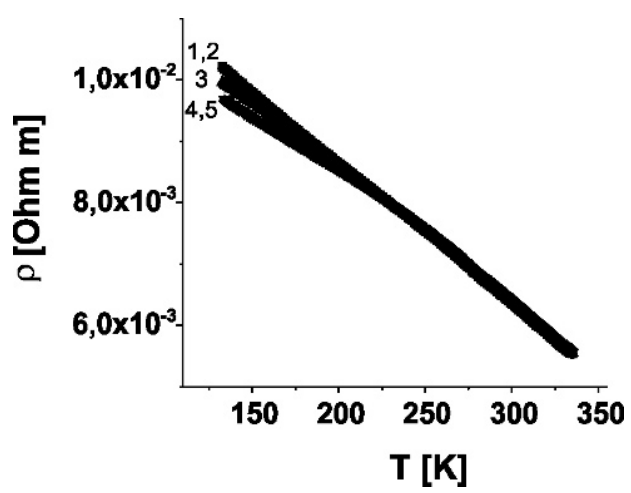

(c)

Fig. 6. Temperature dependences of the real part of the nanocomposites impedance for the set 2 samples with $x=37$ at.\% (a), 42 at.\% (b) and 66 at.\% (c) at frequencies $f=1,5 \mathrm{kHz}(1), 10 \mathrm{kHz}(2)$, $100 \mathrm{kHz}(3), 500 \mathrm{kHz}(4), 1000 \mathrm{kHz}(5)$.

The presence of the maximum in the $\rho(x)$ dependence at low values of $x$ should be considered in terms of some peculiarities in phase composition of oxidized films presented in [1215]. In particular, the films in set 1 , deposited at lower $P_{\mathrm{O}_{2}}$, at $x<50$ at.\% contain mainly superparamagnetic nanoparticles of complex oxides $\mathrm{Fe}^{3+}(\mathrm{Co}, \mathrm{Zr}) \mathrm{O}$ and $\mathrm{Fe}^{2+}(\mathrm{Co}, \mathrm{Zr}) \mathrm{O}$ attributed to the superposition of maghemite $\gamma-\mathrm{Fe}_{2} \mathrm{O}_{3}$ or magnetite $\mathrm{Fe}_{3} \mathrm{O}_{4}$ and wüstite-based $\left(\mathrm{Fe}_{x} \mathrm{Co}_{1-x}\right)_{1-\delta} \mathrm{O}$ oxide. At $x>50$ at.\% large ferromagnetic nanoparticles of $\alpha$ $\mathrm{FeCo}(\mathrm{Zr}, \mathrm{O})$ or their ferromagnetically-interacting agglomerations were detected [12, 14, 15]. Such ferromagnetic nanoparticles should obviously create a current-conductive net of oxidized nanoparticles contacting electrically $[12,14,15]$. At the same time, the films of set 2, deposited at higher $P_{\mathrm{O}_{2}}$, contained only $\mathrm{Fe}^{3+}(\mathrm{Co}, \mathrm{Zr}) \mathrm{O}$ superparamagnetic nanoparticles in the whole composition range. Mössbauer spectroscopy and EXAFS [15] revealed one common feature of the granular FeCoZr-based films deposited in oxygen-containing atmosphere the progressive oxidation of metallic nanoparticles with $x$ increase.

Considering the phase compositions of the films sintered at lower and higher $P_{\mathrm{O}_{2}}$ described above, one can assume that the maxima in $\rho(x)$ curves in Fig. 2 at low $x$ values can be caused by the competition between the progressive oxidation of metallic nanoparticles with $x$ increase (resulting in $\rho(x)$ growth) and a tendency to the formation of less resistive (percolating) net from the oxidized nanoparticles (resulting in $\rho(x)$ drop due to significant decrease of dielectric matrix volume in the films) at $x \rightarrow x_{C}$.

Summarizing the main features of $\rho(f)$ dependences in Figs. 3 and 4, we can see that they are principally different below and above the threshold concentration $x_{C}$, observed on $\rho(x)$ dependences. As can be seen from the comparison of the curves in Fig. 3 for the samples of set 1 with $x \ll x_{C 1}$, the corresponding $\rho(f)$ dependences are linearized in a double logarithmic scale in the high-frequency range. Such behavior looks very similar to the power-like Mott law [16]:

$$
\rho(f) \sim f^{\alpha}
$$

where $\alpha$ is the so-called frequency factor in the dc/ac hopping model [17]. Such behavior of $\rho(f)$ confirms the presence of hopping mechanism in the carrier transport in the examined samples. Note that the frequency region, where law (1) was fulfilled, 
expands with the decreasing temperature for this set of samples. For the samples of set 1 with $x \geq 39$ at.\% this law is satisfied only at the lowest temperatures and at $f>100 \mathrm{kHz}$ (curve 1 in Fig. 2b). Such behavior confirms our assumption mentioned above that for the samples deposited at $P_{\mathrm{O}_{2}}=2.4 \cdot 10^{-3} \mathrm{~Pa}$ (set 1), $x_{C 1}$ can be considered as a concentration at which physical contact of the oxide shells of metallic nanoparticles occurs.

As follows from Fig. 4a, in the samples of set 2, deposited at higher $P_{\mathrm{O}_{2}}=3.7 \cdot 10^{-3} \mathrm{~Pa}$, an increase of impedance as a whole and expanding the frequency range of hopping conductance are observed. These samples also display radical change of the character of $\rho(f)$ dependence when crossing the critical concentration $x_{C 2}$.

The behavior of temperature dependences of the real part of impedance $\rho(T)$ also changes after approaching the abovementioned threshold concentrations $x=x_{C}$ for both sets of the films studied. As can be seen in Fig. 5, for the films deposited at $P_{\mathrm{O}_{2}}=2.4 \cdot 10^{-3} \mathrm{~Pa}$, the sign of $\mathrm{d} \rho(T) / \mathrm{d} T$ for the samples with $x \geq 39$ at.\% is always negative (see Figs. $4 \mathrm{~b}$ and $4 \mathrm{c}$ ) whereas at $x \ll 39$ at.\% the sign of $\mathrm{d} \rho(T) / \mathrm{d} T$ is strongly dependent on frequency (see Figs. 4a). In particular, in the last case the negative values of $\mathrm{d} \rho(T) / \mathrm{d} T$ were observed only at $T>200 \mathrm{~K}$ and at relatively low frequencies $f<50 \mathrm{kHz}$ (see curves 1 and 2 in Fig. 4a). Such behavior of the set 1 films confirms the presence of a certain critical concentration $x_{C 1}$, at which the transition from high-resistive to low-resistive state is observed. Similar changes in the character of $\rho(T)$ curves with $x$ increase in Fig. 6 for the set 2 samples, deposited at $P_{\mathrm{O}_{2}}=3.7 \cdot 10^{-3} \mathrm{~Pa}$, confirm the presence of the threshold concentrations $x_{C 2}$.

The conducted analysis of $\rho(x, T, f)$ dependences in a wide range of temperatures and frequencies indicates that non-metallic (hopping) conductance in the samples $\left(\mathrm{Fe}_{45} \mathrm{Co}_{45} \mathrm{Zr}_{10}\right)_{x}(\mathrm{PZT})_{(100-x)}$ film samples is preserved in the whole range of the examined $x$ values independently of partial pressures of oxygen in vacuum chamber during sputtering. This supports the evidence that for the studied composites with FeCoZr-based nanoparticles, having either "core/shell" or fully oxidized structure, the IMT is not observed even at the highest $x$ values.
At the same time, we can ascertain that in accordance with $[12,14,15]$, the nanoparticles contain more or less complex FeCo-based oxides (either in "shells" or even in "cores" of nanoparticles), which are semiconducting by their nature. Therefore, unlike the $\left(\mathrm{Fe}_{45} \mathrm{Co}_{45} \mathrm{Zr}_{10}\right)_{x}\left(\mathrm{Al}_{2} \mathrm{O}_{3}\right)_{(100-x)}$ film nanocomposites where the IMT is observed at the percolation threshold, in $\left(\mathrm{Fe}_{45} \mathrm{Co}_{45} \mathrm{Zr}_{10}\right)_{x}(\mathrm{PZT})_{(100-x)}$ film nanocomposites, the approaching a certain critical concentration $x_{C}$ is accompanied by the formation of a semiconducting (non-metallic!) net from electrically contacting FeCo-based oxides embedded into PZT matrix.

\section{Conclusions}

The dependences of real part of impedance $\rho$ on frequency and temperature were measured in $\left(\mathrm{Fe}_{45} \mathrm{Co}_{45} \mathrm{Zr}_{10}\right)_{x}(\mathrm{PZT})_{100-x}$ nanocomposite films in a wide range of compositions $25 \leq x \leq 80$ at.\%. The films were deposited by ion-beam sputtering in $\mathrm{Ar}+\mathrm{O}_{2}$ gas mixture at different oxygen pressures. It has been shown that $\rho(x)$ dependences approach a maximum $\rho_{\max }$ between 20 and 35 at. $\%$ and that the position of this maximum is shifted to higher $x$ values with frequency increase. At the approaching of a certain threshold concentration $x_{C} \sim 41$ 46 at. $\%, \rho(x)$ displays a dramatic drop (by 5-6 orders of magnitude) with $x$ increase. The observed $\rho(x)$ dependences can be explained by the competition between the progressive oxidation of metallic nanoparticles with $x$ increase (resulting in $\rho(x)$ growth) and a tendency to the formation of less resistive (percolating) net from oxidized nanoparticles (resulting in $\rho(x)$ drop due to the significant decrease of dielectric matrix volume in the films) at $x \rightarrow x_{C}$.

\section{Acknowledgements}

The work was partially supported by VISBY Program of the Swedish Institute and the Belarusian State Research Programs "Nanomaterials and nanotechnologies" and "Crystalline and molecular structures". Dr Eng. Tomasz N. Kołtunowicz received 2-year fellowship for outstanding young scientists awarded by the Polish Ministry of Science and Higher Education in 2011. 


\section{References}

[1] Skomski R., Condensed Matter, 15 (2003), R841.

[2] BADER S.D., Surface Science, 500 (2002), 172.

[3] Stauffer D., Aharony A., Introduction to percolation theory, London, Taylor \& Francis, 2003.

[4] SaAd A.M., MaZaniK A.V., Kalinin Y.E., Fedotova J.A., Fedotov A.K., WroteK S., Sitnikov A.V., Svito I.A., Reviews on Advanced Materials Science, 8 (2004), 152.

[5] SaAd A., Fedotov A.K., Svito I.A., Fedotova J.A., ANDRIEVSKY B.V., KALININ Y.E., MalyutinaBronskaya V., Patryn A.A., MaZanik A.V., SitNIKOV A., Journal of Alloy and Compounds, 423 No. 1-2 (2006), 176.

[6] KoŁtunowicz T.N., Żukowski P., Fedotova V.V., SaAd A.M., Fedotov A.K., Acta Physica Polonica A, 120 No. 1 (2011), 39.

[7] KoŁtunowicz T.N., Żukowski P., Fedotova V.V., SaAd A.M., Fedotov A.K., Acta Physica Polonica A, 120 No. 1 (2011), 39.

[8] Żukowski P., KoŁtunowicz T., Partyka J., FedoTOVA Y.A., LARKIN A.V., Vacuum, 83 (2009), S275.

[9] Zhukowski P., KoŁtunowicz T.N., Fedotova J.A., LARKIN A.V., Przeglad Elektrotechniczny, 86 No. 7 (2010), 157.

[10] Poklonskiy N.A., Gorbachuk N.I., Basis of the Impedance Spectroscopy of the Composites, Belarusian State University, Minsk, 2005.

[11] Kalinin Yu.E., Ponomarenko A.T., Sitnikov A.V., Stogney O.V., Physics and Chemistry of Materials Treatment, 5 (2001), 14.

[12] Kasyuk Yu.V., Fedotova Yu.A., Marszalek M., KARCZMARSKA A., Mitura-NowaK M., Kalinin
Yu.E., Sitnikov A.V., Solid State Physics, 54, No 1 (2012), 178.

[13] Fedotova J., Kasiuk Yu., Larkin A., Przewoznik J., Kapusta C., Kalinin Yu., Proceedings of the $54^{\text {th }}$ Internationales Wissenschaftliches Kolloquium - Infromation technology and electrical engineering-devices and systems, materials and technology for the future (54-IWK), Ilmenau, Germany, September 7-10, 2009; Ed: F.Berger, Ilmenau University of Technology, 2009, ISBN: 973-1-938843-45-1.

[14] Fedotova J., Koltunowicz T.N., Zhukowski P., Transport tadunków i właściwości strukturalne wybranych nanokompozytów metal-dielektryk, Politechnika Lubelska, 2012.

[15] Przewoznik J., Kapusta C., Milosavljevic M., Kasiuk J.V., Zukrowski J., Sikora M., MAXimenKo A.A., SzePietowsKa D., Homewood K.P., Journal Physics D: Applied Physics, 44 (2011), 495001-1.

[16] Мотт N.F., DAVIS E.A., Electron process in noncrystalline materials, Claredon Press, Oxford, 1979.

[17] Żukowski P., Kołtunowicz T., Partyka J., Wegierek P., Kolasik M., Larkin A.V., Fedotova J.A., Fedotov A.K., Komarov F.F., VlaSukova L.A., Przeglad Elektrotechniczny, 84 No 3 (2008), 247 (in Polish).

Received 29.07.2011

Accepted 16.05.2012 